\title{
СОВЕРШЕНСТВОВАНИЕ ИНФРАСТРУКТУРЫ
}

И МАТЕРИАЛЬНО-ТЕХНИЧЕСКОЙ БАЗЫ ФГУП «АТОМФЛОТ» ДЛЯ ОБЕСПЕЧЕНИЯ ЭКОЛОГИЧЕСКОЙ БЕЗОПАСНОСТИ НА СЕВЕРО-ЗАПАДЕ РОССИИ

\author{
М. М. Кашка, Е. А. Ефанская, В. А. Кобзев, А. Ю. Богданов, Д. А. Ткаченко \\ ФГУП «Атомфлот» (Мурманск, Российская Федерация)
}

Сделан обзор имеющихся производственных мощностей для обращения с отработавшим ядерным топливом (ОЯТ) и радиоактивными отходами (РАО) на ФГУП «Атомфлот» и объема работ по модернизации объектов инфраструктуры, непосредственно задействованных в работах с ОЯТ и РАО, как за счет средств Российской Федерации, так и за счет международной технической помощи. Приведены данные по участию ФГУП «Атомфлот» в работах по реабилитации северо-запада России в части вывоза отработавщего ядерного топлива атомного ледокольного флота и других организаций. Описано состояние выполнения работ по выводу из эксплуатации атомных ледоколов и судов атомнотехнологического обслуживания.

Ключевые слова: атомные ледоколы, отработавщее ядерное топливо, радиоактивные отходы, вывод из эксплуатации.

Статья поступила в редакцию 16 декабря 20162.

\section{Введение}

Безопасное использование атомной энергии на гражданском атомном флоте и осуществление производственной деятельности как в мирных, так и в оборонных целях, на ближайшую перспективу и в долгосрочном периоде, при которых эффективно обеспечивается достижение главной цели экологической политики - сохранение уникальной природной системы арктического региона, поддержание ее целостности и саморегуляции, обеспечение экологической безопасности в северо-западном регионе страны всегда являлись основой при планировании ФГУП «Атомфлот» направлений своей деятельности.

Создание условий для решения задач безопасного обращения с отработавшим ядерным топливом (ОЯТ) и радиоактивными отходами (РАО), накопленными на объектах Мурманской области, путем модернизации объектов инфраструктуры ФГУП «Атомфлот» и при вывозе ОЯТ и РАО из региона - одно из ключевых звеньев политики предприятия, отвечающее всем современным требованиям по безопасности ведения работ в области использования атомной энергии.

В настоящее время ФГУП «Атомфлот» осуществляет эксплуатацию, обслуживание, модернизацию, ремонт и вывод из эксплуатации атомных ледоколов и судов атомно-технологического обслуживания (АТО). Важной частью выполнения указанных функций является обращение с ОЯТ и РАО, которые образуются на всех стадиях жизненного цикла ядерных энергетических установок судов и атомных технологических установок судов АТО.

Береговая инфраструктура ФГУП «Атомфлот» располагает необходимыми производственными мощностями (площадь цехов - более $12500 \mathrm{~m}^{2}$ ) для комплексного ремонта, технологического обслуживания и стоянки судов (длина причальной линии - более 1000 м). Предприятие имеет подъездные железнодорожные пути, которые позволяют принять и разместить вдоль причалов до 40 железнодорожных вагонов. Для проведения грузовых операций используются портальный кран фирмы KONE грузоподъемностью до 100 т и портальный кран КПМ аналогичной грузоподъемности.

Радиоактивные отходы образуются на ФГУП «Атомфлот» в результате деятельности по эксплуатации атомного ледокольного флота. Это различные узлы, детали, приборы, механизмы, инструменты и материалы, имеющие радиоактивные загрязнения 
и наведенную активность и не пригодные к дальнейшему использованию. Также это жидкие и твердые РАО, образующиеся при дезактивации, в процессе ремонтных работ и в результате регламентных работ на реакторной установке, спецодежда и средства индивидуальной защиты, не пригодные для дальнейшего использования.

Важную роль в решении задач по обеспечению экологической безопасности при функционировании ФГУП «Атомфлот» сыграл «Стратегический Мастерплан утилизации и экологической реабилитации выведенных из эксплуатации объектов атомного флота и обеспечивающей инфраструктуры в северозападном регионе России», разработанный по заказу «Росатома» и при научном руководстве ИБРАЭ РАН в 2005-2007 гг. [3]. «По содержанию, широте и глубине охватываемых вопросов и проблем Стратегический Мастер-план (СМП) качественно отличается от разрабатывавшихся ранее ведомственных и федеральных программ по утилизации и экологической реабилитации. СМП имеет всеобъемлющий характер, охватывает все объекты утилизации и экологической реабилитации вне зависимости от их ведомственной принадлежности и, что существенно, рассчитан на длительную перспективу. Таким образом, он сформировал основу системного подхода к решению проблем утилизации и экологической реабилитации радиационно опасных объектов и международного сотрудничества в этой области, что стало залогом высокой эффективности работ и оптимального использования выделяемых средств» [2].

В ряде публикаций [1; 4] уже освещались вопросы, связанные с решением проблем безопасного обращения с ОЯТ и РАО на ФГУП «Атомфлот», но цель настоящей статьи - показать, что только при совершенствовании инфраструктуры и материальнотехнической базы предприятия возможно эффективное обеспечение экологической безопасности на северо-западе России.

\section{Модернизация объектов \\ инфраструктуры ФГУП «Атомфлот»}

С целью создания необходимых условий для обращения с ОЯТ и РАО выполнен большой объем работ по модернизации инфраструктуры ФГУП «Атомфлот» при финансировании Российской Федерации и зарубежных партнеров.

- В рамках федеральной целевой программы (ФЦП) «Модернизация транспортной системы России (2002-2010 годы)» в 2008-2009 гг. на ЗАО «КБ ТяжМаш СПБ» был спроектирован и изготовлен специальный портальный кран грузоподъемностью 100 т для работ с радиоактивными материалами (РМ).

- В 2012 г. выполнен ремонт подкрановых путей на причалах № 3, 4, 5, что позволило обеспечить безопасность при обращении с ядерными материалами, радиоактивными веществами (РB) и РАО при перемещении их по территории предприятия.
А в 2014 г. на территории ФГУП «Атомфлот» выполнены работы по реконструкции причала № 5 . Это позволило швартовать все типы судов с РМ с осадкой до 8 м у причала и сократить маршрут транспортировки РМ по территории предприятия.

- Для обеспечения загрузки ОЯТ всех типов в транспортно-упаковочные контейнеры (ТУК) в 2013 г. построен и принят в эксплуатацию береговой пост загрузки ОЯТ. После завершения строительства появилась возможность выполнять работы по загрузке ОЯТ в контейнеры на берегу в защищенном от внешних воздействий посту загрузки.

- С целью обеспечения безопасности при хранении радиоактивных отходов с 2008 г. проводится планомерная работа по изменению условий хранения накопленных на предприятии твердых радиоактивных отходов (ТРО) и подготовке их к захоронению. В цехах предприятия, предназначенных для обращения с РАО, проведена модернизация и оборудованы участки кондиционирования ТРО всех степеней активности. На этих участках проводятся работы по кондиционированию РАО и подготовка их к передаче национальному оператору на захоронение.

- В 2008-2011 гг. модернизирована технологическая линия обращения с горючими ТРО, расположенная в хранилище твердых отходов. Технология сжигания отходов заменена на технологию прессования. Модернизированная технология позволила проводить кондиционирование горючих и других прессуемых низкоактивных РАО в стандартные металлические бочки с использованием пресса.

- В 2008 г. для обеспечения работ по вывозу ОЯТ из поселка Гремиха и губы Андреева была выполнена модернизация теплохода «Серебрянка». На судне оборудованы пост загрузки ОЯТ в ТУК и хранилище для размещения ТУК. В 2011 г. дополнительно выполнены работы по оборудованию на судне мест крепления для транспортировки 20-футовых контейнеров с ТРО. Таким образом, судно стало многофункциональным транспортным средством для перевозки ОЯТ и РАО.

- Для улучшения контроля безопасности выполняемых работ в 2008-2009 гг. модернизирована автоматизированная система радиационного контроля, что позволило объединить в единый комплекс системы радиационного контроля предприятия.

Общая сумма финансирования из бюджета России модернизации объектов инфраструктуры, используемых для обращения с ЯТ и РАО, составила более 1 млрд руб.

Международное взаимодействие с целью создания безопасных условий обращения с ОЯТ и РАО на ФГУП «Атомфлот» и обеспечения реабилитации береговых технических баз Северного флота, переданных в ведение Госкорпорации «Росатом», началось в 1996 г. За это время выполнены следующие работы:

- К 2006 г. на предприятии была построена накопительная площадка для временного транзитного хранения контейнеров с ОЯТ ВМФ при вывозе ОЯТ 
на переработку. Проект профинансирован Норвегией и США. Создание площадки позволило разделить морскую и железнодорожную составляющие вывоза ОЯТ для обеспечения увеличения пропускной способности пункта перевалки ОЯТ на ФГУП «Атомфлот». В настоящее время площадка активно используется.

- Для обеспечения мониторинга работ, выполняемых на накопительной площадке ОЯТ, а также мониторинга сбросов и выбросов радиоактивных веществ при переработке жидких радиоактивных отходов (ЖРО) с 2002 по 2004 гг. в рамках программы AMEC 1-5.1 реализован проект создания автоматизированной системы радиационного мониторинга накопительной площадки и ЖРО. Система выполнена на базе норвежского программного комплекса Picasso. Донором проекта выступил Институт энергетических технологий (Норвегия).

- В 2008-2011 гг. в рамках ФЦП специалисты ИБРАЭ РАН СОВМеСТнО С ОАО «ВНИПИЭТ», НПП «Доза» и ООО «ТехноЦентр сервис» провели модернизацию автоматизированной системы контроля радиационной обстановки ФГУП «Атомфлот» с увеличением количества постов радиационного контроля на территории предприятия, в санитарно-защитной зоне и зоне наблюдения и их интеграцией в систему с общим сервером и единым программным обеспечением.

- В начале 2003 г. Минатом России инициировал строительство хранилища отработавшего ядерного топлива контейнерного типа на ФГУП «Атомфлот». Задача проекта - обеспечение экологической безопасности хранения неперерабатываемого ОЯТ, размещенного на тот момент в хранилищах плавучей технической базы (ПТБ) «Лотта» при использовании ее для вывоза ОЯТ с атомных подводных лодок (АПЛ). Работы по проектированию и строительству хранилища завершены в 2006 г. Поставка 50 ТУК-120 для хранения неперерабатываемого ОЯТ, выгружаемого с ПТБ «Лотта», была завершена в 2008 г. Параллельно проводились работы по подготовке неперерабатываемого ОЯТ к загрузке в контейнеры и установке их на длительное хранение. 6 июня 2015 г. работы по разделению отработавших топливных сборок (ОТВС) были завершены, последний 50-й контейнер установлен на хранение.

- В 2008 г. был реализован проект создания интегрированной системы физической защиты ФГУП «Атомфлот», профинансированный правительством Великобритании. Реализация проекта позволила повысить защищенность ядерно и радиационно опасных объектов предприятия и создать локальную зону физической защиты вокруг объектов, входящих в инфраструктуру обращения с ОЯТ.

- В рамках соглашений с Ливерморской национальной лабораторией (Министерство энергетики США) была выполнена модернизация системы физической защиты ФГУП «Атомфлот».

- Монтаж универсального портального монтажного крана КПМ 100/30-30/69-10,5К, предназначенного для работ с РМ на 5-м и 6-м причалах ФГУП «Атомфлот», произведен за счет средств Комиссариата по атомной энергетике Франции. Ввод в 2015 г. в строй нового крана позволил существенно повысить безопасность транспортно-технологических операций со свежим и отработавшим ядерным топливом и снизить риски простоя, вызванные износом и моральным старением ранее использовавшегося для этих целей портального крана KONE (изготовление крана производилось за счет средств ФЦП «Обеспечение ядерной и радиационной безопасности на 2008 год и на период до 2015 года»).

- Правительство Италии профинансировало работы по строительству судна для транспортировки ОЯТ и РАО «Россита». Цель проекта - создание многофункционального морского транспортного средства, обеспечивающего перевозки ОЯТ и РАО на ФГУП «Атомфлот» в различных существующих упаковочных комплектах из мест их нахождения для перегрузки на железнодорожный транспорт или в пункт долговременного хранения реакторных отсеков (ПДХРО) «Сайда». Проект реализован в 2013 г.

- С 2014 по 2016 гг. реализован проект улучшения экологического контроля, донором которого выступил МИД Норвегии через норвежский Институт энергетических технологий. В рамках проекта поставлено оборудование для лаборатории контроля внешней среды. Оно дало возможность существенно повысить эффективность и производительность работы, позволяя с большой точностью и оперативно исследовать пробы сточной, морской и ливневой воды.

\section{Обращение с ОЯТ и РАО \\ на ФГУП «Атомфлот»}

Хранилище ТРО. В настоящее время в хранилище осуществляется хранение некондиционированных ТРО всех уровней активности, а также размещается модернизированная в рамках ФЦП «Обеспечение ядерной и радиационной безопасности на 2008 год и на период до 2015 года» технологическая линия по обращению с горючими ТРО. На площадях хранилища имеется участок кондиционирования средне- и высокоактивных отходов.

Временное хранилище кондиционированных TPO. В хранилище размещены подготовленные к передаче для окончательного захоронения кондиционированные ТРО в контейнерах типа НЗК.

Открытые площадки хранения ТРО. На площадках размещены высокоактивные крупногабаритные РАО в виде выемных экранных сборок (сб. 03) в контейнерах БК, крупногабаритные низкоактивные РАО в виде не подлежащего дальнейшему использованию технологического оборудования и пустые контейнеры-сборники для ТРО. Под данные виды отходов проектом хранилища твердых отходов (ХTO) не предусмотрено мест хранения. Контейнеры с высокоактивными сб. 03 дополнительно для снижения мощности дозы на причале № 5 и влияния 
Таблица 1. Количество ОТВС и кассет, отправленных на ФГУП «ПО “Маяк” через ФГУП «Атомфлот»

\begin{tabular}{|l|c|c|c|c|c|c|c|c|c|}
\hline $\begin{array}{c}\text { Участники } \\
\text { работ }\end{array}$ & $\mathbf{2 0 0 8}$ & $\mathbf{2 0 0 9}$ & $\mathbf{2 0 1 0}$ & $\mathbf{2 0 1 1}$ & $\mathbf{2 0 1 2}$ & $\mathbf{2 0 1 3}$ & $\mathbf{2 0 1 4}$ & $\mathbf{2 0 1 5}$ & $\mathbf{2 0 1 6}$ \\
\hline «Атомфлот» & - & 459 & 0 & 105 & 409 & 805 & 794 & 709 & 708 \\
\hline $\begin{array}{l}\text { Другие } \\
\text { организации }\end{array}$ & 260 & 1396 & 290 & 504 & 245 & 398 & 448 & $\begin{array}{c}511 \text { ОТВС } \\
104 \text { кассеты }\end{array}$ & $\begin{array}{c}110 \text { кассет } \\
\text { (10 ТУК-108/1) }\end{array}$ \\
\hline Итого ОТВС & 260 & 1855 & 290 & 609 & 654 & 1203 & 1242 & 1220 & 708 \\
\hline Итого кассет & - & - & - & - & - & - & - & 104 & 110 \\
\hline
\end{tabular}

атмосферных осадков укрыты биозащитой, состоящей из набора колец и крышки с толщиной стенки 300 мм, залитых бетоном.

С 2008 г. при реализации в рамках ФЦП «Обеспечение ядерной и радиационной безопасности на 2008-2015 годы» мероприятия по изменению условий хранения твердых радиоактивных отходов ФГУП «Атомфлот» и подготовки их к захоронению с открытых площадок, прилегающих к ХTO, удалено 640 контейнеров с низкоактивными ТРО.

В ФЦП «Обеспечение ядерной и радиационной безопасности на 2016-2020 годы и на период до 2025 года» внесено проведение работ по изменению условий хранения твердых радиоактивных отходов и подготовки их к захоронению и запланировано продолжение работ по очистке открытых площадок, примыкающих к ХTO, и подготовке к реабилитации данной территории.

В основу технологии обращения с ТРО легли технологические линии:

- сортировки и кондиционирования горючих (прессуемых) ТРО;

- кондиционирования негорючих ТРО и дезактивации металлических ТРО;

- кондиционирования средне- и высокоактивных отходов.

В рамках реализации ФЦП «Обеспечение ядерной и радиационной безопасности на 2016-2020 годы и на период до 2030 года» с территории ФГУП «Атомфлот»:

- вывезены и переданы на захоронение национальному оператору по обращению с РАО 52 контейнера типа НЗК с кондиционированными РАО объемом $188 \mathrm{M}^{3}$;

- транспортированы на судоремонтный завод (СРЗ) «Нерпа» (филиал АО «ЦС “Звездочка”») 27 контейнеров типа НЗК с кондиционированными РАО и 74 бочки типа Б31А2-216,5 с РАО, образованными в результате выполнения комплекса работ по утилизации ПТБ «Лепсе», объемом 67,3 м³.

Таким образом, в настоящее время ФГУП «Атомфлот» обеспечивает безопасное обращение и хранение ТРО до момента передачи национальному оператору на захоронение.

В области обращения с ОЯТ на территории ФГУП «Атомфлот» создан современный производственный комплекс, обеспечивающий безопасность всех работ по обращению с ОЯТ атомного ледокольного флота, таких как:

- выполнение перезарядок реакторных установок действующих атомных ледоколов;

- отправка на переработку ОЯТ атомного ледокольного флота;

- вывоз морским путем ОЯТ утилизируемых АПЛ, перевалка его на железнодорожный транспорт и отправка на переработку;

- вывоз морским путем ОЯТ из хранилищ губы Андреева и поселка Гремиха, перевалка его на железнодорожный транспорт и отправка на переработку;

- перевалка ОЯТ исследовательских реакторов с морского на железнодорожный транспорт и отправка его на переработку;

- транзитное хранение ОЯТ до отправки на переработку;

- долговременное контейнерное хранение неперерабатываемого ОЯТ атомного ледокольного флота.

ФГУП «Атомфлот» принимает непосредственное участие в работах по реабилитации бывших военноморских баз Северного флота в части транспортировки, временного хранения и перегрузок ОЯТ выведенных из состава флота и утилизируемых АПЛ (табл. 1).

Вывоз ОЯт обеспечивается судами АТО ФГУП «Атомфлот» - плавучей технологической базой «Имандра», теплоходом «Серебрянка» и судномконтейнеровозом для транспортировки ОЯТ и РАО «Россита». Перегрузка контейнеров производится на территории ФГУП «Атомфлот» посредством специализированного портального крана КПМ 100/30-30/69-10,5К. Загрузка выполняется либо на накопительную площадку, либо сразу в спецэшелон для отправки на переработку на ФГУП «ПО “Маяк"».

К настоящему времени из Гремихи вывезено более 50\% хранящегося ОЯТ, полностью очистить военно-морскую базу от ОЯТ планируется к 2020 г. Начало работ по вывозу ОЯТ из ВМБ губы Андреева запланировано на 2017 г. при использовании теплохода «Россита».

С 2008 г. было вывезено 16 загрузок реакторов атомных ледоколов и 14 загрузок реакторов других организаций. 
В 2016 г. «Атомфлот» фактически избавился от своих запасов отработавшего ядерного топлива, готового к отправке на ПО «Маяк». Также впервые был осуществлен вывоз радиоактивных отходов с последующей передачей национальному оператору по обращению с РАО. На данный момент «Атомфлот» работает в режиме ненакопления ОЯТ и РАО.

Говоря о реабилитации бывших баз Северного флота в северо-западном регионе России, невозможно не упомянуть о проектах, реализуемых в рамках материальной технической помощи нашими зарубежными партнерами. Так, за счет средств Министерства экономического развития Италии в 2011 г. было построено специализированное судно «Россита», без которого вывоз ОЯТ и РАО с ВМБ был бы весьма затруднен. Кроме того, при финансировании итальянского правительства в 2016 г. были изготовлены и доставлены в Россию на теплоходе «Россита» 10 контейнеров типа ТУК-143 и сопутствующее оборудование к ним. Это позволило отработать на макетах обращение с отработавшим топливом других организаций и в будущем обеспечить вывоз ОЯТ.

\section{Вывод из эксплуатации атомных ледоколов и судов АТО на ФГУП «Атомфлот»}

ПТБ «Володарский» с 1969 по 1991 гг. использовалась для работ по перезарядке реакторов атомных ледоколов. В рамках ФЦП «Обеспечение ядерной и радиационной безопасности России на 2008-2015 годы» было предусмотрено финансирование работ по выводу из эксплуатации ПТБ «Володарский». Общая стоимость работ по утилизации составила 160,9 млн руб.

Работы по утилизации судна выполнял СЗЦ «СевPAO» - филиал ФГУП «РосРАО» в отделении «Сайда-Губа» с июля 2013 г. по ноябрь 2014 г.

Были выполнены следующие этапы работ:

- конвертация корпуса судна;

- буксировка судна от причалов ФГУП «Атомфлот» на акваторию ПДХРО «Сайда»;

- постановка ПТБ «Володарский» в плавучий док ПД-42 и перевод на стапельную плиту;

- разделение судна на блоки;

- утилизация корпусных конструкций и оборудования судна.

В результате были сформированы две блокупаковки, размещенные для долговременного хранения в ПДХРО «Сайда». Продукты утилизации ПТБ «Володарский» в виде металлолома реализованы на открытом аукционе в конце 2014 г.

Утилизация ПТБ «Володарский» позволила улучшить радиационную обстановку в акватории Кольского залива и существенно снизить риски неконтролируемого распространения радиоактивных веществ.

ПТБ «Лепсе» в 1961 г. была переоборудована для использования в качестве плавучей технологической базы и до 1981 г. использовалась для перезарядки реакторов судов атомного ледокольного флота, в дальнейшем применялась только для хранения ОЯТ, РАО, технологической оснастки и оборудования.

Многолетняя эксплуатация ПТБ «Лепсе» породила серьезную проблему, связанную с обеспечением ядерной и радиационной безопасности в северо-западном регионе России в связи с накоплением на судне дефектного отработавшего ядерного топлива.

Работы по выводу из эксплуатации ПТБ «Лепсе» финансируются из федерального бюджета и за счет международной технической помощи (Фонда поддержки «Экологического партнерского Северного измерения»). Международное сотрудничество по проекту утилизации ПТБ «Лепсе» началось в 1994 г.

Подготовка ПТБ «Лепсе» к утилизации проводилась с 2012 по 2014 гг. специалистами ФГУП «Атомфлот» и СРЗ «Нерпа». В октябре 2014 г. ПТБ «Лепсе» была переведена на открытую стапельную плиту СР3 «Нерпа», и судно было разделено на блоки, демонтированы корпусные конструкции и оборудование, сформирована кормовая блок-упаковка и произведена ее транспортировка для долговременного хранения в ПДХРО «Сайда».

В настоящее время СРЗ «Нерпа» ведет работы по формированию носовой блок-упаковки, изготавливаются и монтируются ее секции, продолжается подготовка к реализации и захоронению продуктов утилизации. Также на стапельной плите СРЗ «Нерпа» начаты работы по возведению специального защитного укрытия, в котором будет выгружаться отработавшее ядерное топливо. После выгрузки ОЯТ и отправки его на переработку окончательно сформированная носовая блок-упаковка ПТБ «Лепсе», возможно, будет транспортироваться в ПДХРО «Сайда».

Атомный ледокол проекта 1052 «Сибирь» эксплуатировался с 1977 по 1992 гг. В 2013 г. ОАО «НИПТБ «Онега» был разработан проект утилизации ледоколов проекта 1052 (10521), который предусматривает разделку корпуса судна и формирование блок-упаковки реакторного отсека на твердом основании. Для этого необходимо выполнить комплекс работ по демонтажу крупногабаритного оборудования на плаву и дальнейших доковых операций.

В 2015 г. проведены технико-экономические исследования вариантов вывода из эксплуатации ледоколов в связи с появлением новых технологий и информации. Исследования опирались на радиационные обследования реакторных установок атомных ледоколов «Сибирь» и «Россия» с учетом разработанной технологии поэлементного демонтажа реакторных установок большого атомного корабля «Урал». Был принят вариант утилизации атомных ледоколов с выгрузкой атомной паропроизводящей установки (АППУ) на плаву, позволяющий:

- снизить затраты на утилизацию, в том числе за счет исключения работ по разделке корпусов судов; - сократить сроки утилизации; 
- вывести ледокол из категории радиационных источников для продажи без разделки корпуса на металлолом.

В результате в 2016 г. была разработана и утверждена Госкорпорацией «Росатом» «Концепция утилизации судов с ядерными энергетическими установками (атомные ледоколы проекта 1052, 10521) и судов атомного технологического обслуживания».

По итогам аукциона в 2016 г. предприятием-исполнителем работ по утилизации атомного ледокола «Сибирь» стал филиал «СРЗ “Нерпа” АО «ЦС “Звездочка"». Общая стоимость работ составляет 785 млн руб., срок выполнения - 30 ноября 2017 г. При этом сокращение расходов на утилизацию по сравнению с предусмотренным ранее объемом финансирования из федерального бюджета составит около 1 млрд руб.

При реализации этого проекта должны быть выполнены работы по демонтажу оборудования реакторных установок атомного ледокола «Сибирь» на плаву. Дальнейшее размещение оборудования АППУ в блок-упаковке с последующим долговременным хранением на специально оборудованной береговой площадке ПДХРО «Сайда» позволит минимизировать риски воздействия факторов, способных привести к несанкционированному распространению РВ в окружающую среду.

После демонтажных работ судно перестает быть радиационно опасным объектом, и появляется возможность продажи его в целом для разделки на металлолом или создания другого плавучего объекта.

В настоящее время атомный ледокол «Сибирь» подготовлен к утилизации и отбуксирован 1 ноября 2016 г. от ФГУП «Атомфлот» на акваторию СРЗ «Нерпа» для реализации государственного контракта на выполнение работ по демонтажу реакторного оборудования судна, формированию блок-упаковки и размещению ее в ПДХРО «Сайда».

Утилизация ПТБ «Лотта» запланирована на период после 2020 г., но не ранее ввода в строй новой плавучей технической базы для обслуживания атомных ледоколов проекта 22220 с реакторной установкой РИТМ-200. Согласно федеральной целевой программе «Обеспечение ядерной и радиационной безопасности на 2016-2020 годы и на период до 2030 года» в 2018-2019 гг. запланирована утилизация атомного ледокола «Арктика». Работы будут проводиться по той же схеме, что и с ледоколом «Сибирь». На очереди - ледокол «Россия». Кроме того, в 2016 г. принято решение о выводе из эксплуатации ядерной установки ледокола «Советский Союз». В середине 2017 г. судно будет переведено В «холодный отстой».

В заключение необходимо отметить, что совершенствование инфраструктуры и материально-технической базы предприятия позволяет решать накопленные проблемы с ОЯТ и РАО (вывод из эксплуатации, обеспечение приемлемого уровня безопасности), а также создавать современные системы обеспечения безопасности (контроль, учет, аварийное реагирование, мониторинг, медико-санитарное обеспечение), что является определяющим фактором экологической безопасности на северо-западе России.

\section{Литература}

1. Кашка М. М., Абрамов А. Н., Честных И. П. Создание регионального центра перегрузки отработавшего ядерного топлива на ФГУП «Атомфлот» // Арктика: экология и экономика. - 2013. - № 2 (10). - C. 72-79.

2. Саркисов А. А. «Дорожная карта» по снижению угроз на Северо-западе. — URL: http://www.atomicenergy.ru/interviews/2009/09/10/5839.

3. Стратегический Мастер-план утилизации и экологической реабилитации выведенных из эксплуатации объектов атомного флота и обеспечивающей инфраструктуры в северо-западном регионе России: Резюме. - М.: ИБРАЭ РАН, 2007. - 102 с.

4. Филиппов М. П., Абрамов А. Н., Кашка М. М. и др. Проблема плавучей технической базы «Лепсе» // Арктика: экология и экономика. - 2014. - № 1 (13). - С. 80-87.

Источники финансирования исследования: внутренние источники ФГУП «Атомфлот».

\section{Информация об авторах}

Кашка Мустафа Мамединович, заместитель генерального директора — главный инженер, ФГУП «Атомфлот» (183017, Россия, Мурманск-17), e-mail: kashkamm@rosatomflot.ru.

Ефанская Екатерина Александровна, руководитель группы сопровождения целевых программ, ФГуП «Атомфлот» (183017, Россия, Мурманск-17), e-mail: efanskayaea@rosatomflot.ru.

Кобзев Виталий Александрович, инженер 1-й категории, ФГУП «Атомфлот (18301 7, Россия, Мурманск-17) e-mail: kobzevva@rosatomflot.ru.

Богданов Андрей Юрьевич, ведущий специалист, ФГУП «Атомфлот» (183017, Россия, Мурманск-17), e-mail: bogdanovay@rosatomflot.ru.

Ткаченко Дмитрий Андреевич, специалист 1-й категории, ФГУП «Атомфлот» (183017, Россия, Мурманск-17), e-mail: tkachenkoda@rosatomflot.ru.

\section{Библиографическое описание данной статьи}

Кашка М. М., Ефанская Е. А., Кобзев В. А. и др. Совершенствование инфраструктуры и материально-технической базы ФГУП «Атомфлот» для обеспечения экологической безопасности на северо-западе России // Арктика: экология и экономика. — 2017. — № 1 (25). — С. 130—136. 


\title{
MODERNIZATION OF FSUE ATOMFLOT INFRASTRUCTURE AND MATERIAL AND TECHNICAL RESOURCES AIMED AT PROVISION OF ENVIRONMENTAL SAFETY IN THE NORTHWEST OF RUSSIA
}

\author{
Kashka M. M., Efanskaya E. A., Kobzev V. A., Bogdanov A. Yu., Tkachenko D. A.
}

FSUE Atomflot, (Murmansk, Russian Federation)

\begin{abstract}
The article reviews FSUA Atomflot assets and facilities used to manage spent nuclear fuel (SNF) and radioactive wastes (RW), their modernization and development, as well as sources of the aforementioned processes financing, which include both Russian Federation and International funding. FSUE Atomflot participation in the environmental rehabilitation of the Northwest of Russia is analyzed, part of which is the status of retired atomic icebreakers and special maintenance vessels decommissioning.

The key direction of FSUE Atomflot policy is safe handling of spent nuclear fuel and radioactive wastes accumulated by the Company itself and other organizations in Murmansk region. Modernization of FSUE Atomflot infrastructure and material and technical resources is meant to solve this task.

FSUE Atomflot operates state atomic icebreaking fleet, which includes commercial operation, maintenance, modernization, repair and decommissioning of nuclear-powered icebreakers and special maintenance vessels. Handling of spent nuclear fuel and radioactive wastes that are accumulated during the process of operation through the assets life cycle is an important part of the Company's activity.

The important role in the provision of environmental safety belongs to the Strategic Master Plan for Decommissioning of Retired Russian Nuclear Fleet and Environmental Rehabilitation of Its Supporting Infrastructure in the Northwest of Russia, which was ordered by Rosatom and developed under scientific guidance by Nuclear Safety Institute of Russian Academy of Science.

The article further describes the process of SNF and RW handling by FSUE Atomflot, brings up the statistical data of the materials management and transportation. Second part of the article describes the decommissioning of atomic icebreakers and maintenance vessels as part of the environmental safety provision process. The current status of the process, results and development plans are resumed.
\end{abstract}

Keywords: atomic icebreakers, spent nuclear fuel, radioactive wastes, decommissioning

\section{References}

1. Kashka M. M., Abramov A. N., Chestnykh I. P. Sozdaniye regionalnogo tsentra peregruzki otrabotavshego yadernogo topliva na FGUP «Atomflot». [Establishment of the spent nuclear fuel overload regional center on the FSUE «Atomflot»]. Arktika: ekologiya i ekonomika, 2013, no 2 (10), pp 72-79. (In Russian).

2. Sarkisov A. A. «Dorozhnaya karta» po snizheniyu ugroz na Severo-zapade. [Road Map for the Diminishing of Threats in the North-West], September 10, 2009. URL: http:// www.atomic-energy.ru/interviews/2009/09/10/5839 (In Russian)..

3. Strategicheskiy Master-plan utilizatsii i ekologicheskoy reabilitatsii vyvedennykh iz ekspluatatsii obyektov atomnogo flota i obespechivayushchey infrastruktury $v$ severo-zapadnom regione Rossii. [Strategic Master Plan for Decommissioning of Retired Russian Nuclear Fleet and Environmental Rehabilitation of Its Supporting Infrastructure in the Northwest of Russia]. M., IBRAE RAN, rezyume, 2007, 102 p. (In Russian).

4. Filippov M. P., Abramov A. N., Kashka M. M. et al. Problema plavuchey tekhnicheskoy bazy «Lepse» [The problem of floating maintenance base «Lepse»]. Arktika: ekologiya i ekonomika, no 1 (13), 2014, pp 80-87. (In Russian).

Source of research funding: FSUE Atomflot internal funding

\section{Information about the authors}

Kashka Mustafa Mamedinovich, Fisrt Deputy to Director General - Chief Engineer, FSUE Atomflot (Murmansk-17, 183017, Russia), e-mail: kashkamm@rosatomflot.ru.

Efanskaya Ekaterina Aleksandrovna, Head of Target Programs Support Office, FSUE Atomflot (Murmansk-17, 183017, Russia), e-mail: efanskayaea@rosatomflot.ru.

Kobzev Vitaliy Aleksandrovich, 1 st Category Officer, Radioactive Materials Management Office, FSUE Atomflot (Murmansk-17, 183017, Russia), e-mail:kobzevva@rosatomflot.ru.

Bogdanov Andrey Yuryevich, Lead Specialist, Target Programs Support Office, FSUE Atomflot (Murmansk-17, 183017, Russia), e-mail: bogdanovay@rosatomflot.ru.

Tkachenko Dmitriy Andreyevich, 1st Category Officer, Target Programs Support Office, FSUE Atomflot (Murmansk-17, 183017, Russia), e-mail: tkachenkoda@rosatomflot.ru.

\section{Bibliographic description}

Kashka M. M., Efanskaya E. A., Kobzev V. A. et al. Modernization of FSUE Atomflot Infrastructure and Material and Technical Resources Aimed at Provision of Environmental Safety in the Northwest of Russia. The Arctic: ecology and economy, 2017, no 1 (25), pp 130-136. (In Russian).

๔ Kashka M. M., Efanskaya E. A., Kobzev V. A., Bogdanov A. Yu., Tkachenko D. A., 2017 